\title{
Stage IV Major Salivary Gland Carcinoma with Metastasis
}

National Cancer Institute

\section{Source}

National Cancer Institute. Stage IV Major Salivary Gland Carcinoma with Metastasis. NCI

Thesaurus. Code C5899.

Stage IV carcinoma of the major salivary glands with regional lymph nodes and/or distant metastases. 